\title{
Tribocorrosion Behavior of Ti6Al4V Coated with a Bio-absorbable Polymer for Biomedical Applications
}

\author{
Júlio C. M. Souza ${ }^{1,3} \cdot$ Henrique A. Tajiri ${ }^{1} \cdot$ Carolina S. Morsch $^{1} \cdot$ Mihaela Buciumeanu $^{2}$ • \\ Mathew T. Mathew ${ }^{4}$ Filipe S. Silva ${ }^{3} \cdot$ Bruno Henriques $^{1,3}$
}

Received: 15 July 2015/Revised: 23 September 2015/Accepted: 25 September 2015/Published online: 5 October 2015

(C) Springer International Publishing Switzerland 2015

\begin{abstract}
The modification of titanium-based surfaces has been recently studied to accelerate the osseointegration process of endosseous implants. Indeed, bioabsorbable polymer veneers carrying antimicrobials or bone growth factors to the implant-bone interface could enhance such osseointegration process. The main aim of this work was to study the tribocorrosion behavior of veneering biodegradable poly(D,L-lactide) on titanium surfaces in an artificial saliva solution. Cylinders of Ti6Al4V were prepared by grit-blasting with $250-\mu \mathrm{m}$ alumina particles followed by $\mathrm{HF} / \mathrm{HNO}_{3}$ etching technique to increase the roughness of the top surface. After surface modification and cleaning, the rough surface was covered with poly (D,L-lactic acid) (PDLLA) by spin-coating technique. Reciprocating sliding tests were performed against an alumina ball at a normal load of $0.5 \mathrm{~N}$, a sliding frequency of $1 \mathrm{~Hz}$, and linear displacement amplitude of $3 \mathrm{~mm}$ using a tribometer. The sliding tests associated to open-circuit potential (OCP) measurements were performed in artificial saliva solution to mimic the oral conditions for $60 \mathrm{~min}$. After tribocorrosion tests, the worn surfaces were inspected by scanning
\end{abstract}

Júlio C. M. Souza

julio.c.m.souza@ufsc.br; jsouza@dem.uminho.pt

1 Center for Research on Dental Implants (CEPID), PostGraduation Program in Dentistry (PPGO), School of Dentistry (ODT), Federal University of Santa Catarina (UFSC), Florianópolis, SC 88040-900, Brazil

2 Cross-Border Faculty of Humanities, Economics and Engineering, "Dunărea de Jos" University of Galati, Domneasca 47, 800008 Galati, Romania

3 Center for Electromechanical Systems (CMEMS), University of Minho, Campus Azurém, 4800-058 Guimarães, Portugal

4 Section of Tribology, Department of Orthopedics, Rush University Medical Center, Chicago, IL 60612, USA electron microscopy. The results revealed a lower coefficient of friction (COF) on PDLLA than that recorded on Ti6Al4V. A protective effect of PDLLA against wear and corrosion of Ti6Al4V was noticed on the reciprocating sliding under OCP measurements for $60 \mathrm{~min}$. Furthermore, a gradual degradation of PDLLA was detected, which could be useful in situ to release of therapeutic substances to be incorporated into the bioabsorbable polymer.

Keywords Bioabsorbable polymer - PDLLA - Ti6Al4V . Tribocorrosion · Biotribocorrosion

\section{Introduction}

Titanium and its alloys have been the first choice materials for implant systems and prosthetic structures in oral rehabilitation due to their properties such as low density (about $4.5 \mathrm{~g} / \mathrm{cm}^{3}$ ), low elastic modulus (110-140 GPa), high mechanical strength (tensile strength of about $950 \mathrm{MPa}$ ), high corrosive resistance, and also excellent biocompatibility [1-3]. In fact, the corrosion resistance and biocompatibility of titanium and its alloys are a consequence of a protective and compact thin film, based mainly on $\mathrm{TiO}_{2}$, formed on titanium surface. However, the titanium passive film can be destroyed in the presence of corrosive substances (e.g., fluorides) and/or wear in the oral cavity [4]. As a result, the release of metallic ions and oxide particles to surrounding environment due to degradation has a toxic potential to human tissues and, as a consequence, may induce chronic peri-implant inflammations that can develop bone loss and even subsequently implant loss [5].

The modification of titanium surface by several techniques has been studied to improve biocompatibility and 
osseointegration [6, 7]. Various methods have been focusing to generate a rough implant surface by titanium plasma-spraying or grit-blasting with hard ceramic particles followed by acid etching treatment, named SLA method [8, 9]. Recent methods have focused on the bioactivity and wettability of the implants modifying the titanium surface with hydroxyapatite, beta- TCP- or Ca/Pbased coatings $[8,9]$. Nowadays, such modifications involve electrochemical techniques such as anodization and other physicochemical processes. Novel techniques are proposed to modify the titanium implant surfaces with biomolecules such as growth factors (e.g., BMP, TGF- $\beta$, PDGF), adhesive proteins, or organic antimicrobials. However, those biomolecules can be detached due to the friction against bone during implant placement $[8,9]$.

Synthetic or natural coatings based on polymers, glasses, or composites are tested on biomaterials based on titanium, stainless steel, and $\mathrm{CoCr}$ alloys for different applications ranging from engineering to medicine [1012]. Such applications involve orthopedic or dental implants, electronic semiconductors, sport equipment, automotive, and aircraft structures. Considering biocompatible polymer veneers, the poly (D,L-lactic acid) (PDLLA) is a bioabsorbable polymer that can improve interactions at the implant-tissue interface acting as a locally drug-delivery system [6]. For instance, PDLLA can incorporate drugs (e.g., antimicrobials or growth factors) which can be continuously released at the implant-tissue area over a period of several weeks. Antimicrobials would reduce bacterial colonization at the implant-tissue interface while growth factors could accelerate the osseointegration process [6, 13-15]. Also, the veneering PDLLA to implant surface can decrease the friction between titanium and bone, reducing the temperature at the interface, as well as it can avoid the titanium degradation during implant placement. As a consequence, a decrease of titanium degradation prevents the release of metallic ions.

The processing route to cover metallic surfaces by coatings has a big influence on the adhesion and performance of the veneering biomaterial. The deposition of polymers on metallic substrate have been prepared using various methods such as thermal spraying [16], painting, spinning, suspension spraying, electroplating, etc [17]. However, mechanical and microscopic analyses are required to evaluate the in vitro and in vivo performances of the polymer to metallic substrate interfaces. Regarding the fact that implants undergo friction against bone during placement, wear tests on polymer veneers immersed in simulated physiologic solutions are interesting to evaluate the simultaneous degradation by corrosion and wear. The combination of mechanical (wear) and electrochemical (corrosion) interactions on surfaces submitted to contact movement is a process known as tribocorrosion. This process causes irreversible transformation of a material. Biomaterials are vulnerable to this process, and most often there is a loss of material that can lead to failures and reduce the long-term success of these products [18].

The main aim of this work was to study the tribocorrosion behavior of veneering biodegradable poly(D,L-lactide) on Ti6Al4V surfaces by reciprocating sliding tests in an artificial saliva solution. It was hypothesized that PDLLA could decrease the friction on Ti6Al4V surfaces during wear sliding.

\section{Materials and Methods}

\subsection{Synthesis of the Samples}

Thirty cylindrical samples $(8 \mathrm{~mm}$ diameter and $4 \mathrm{~mm}$ thick) were cut from Ti6Al4V (VSMPO TIRUS, US, ASTM B 348, Grade V) bars and wet ground on SiC abrasive papers down to 1200 mesh. After grinding, the samples were ultrasonically cleaned in isopropyl alcohol for $10 \mathrm{~min}$ and distilled water in a desiccator for $24 \mathrm{~h}$ before performing tribocorrosion tests.

The metallic substrate surface was air braded with alumina particles $(\sim 250 \mu \mathrm{m})$ with an impact angle of $90^{\circ}$ under a pressure of 5 bar at a distance of $80 \mathrm{~mm}$ from the surface to obtain a rough surface, accordingly to the procedures reported by previous studies [9, 16, 19, 23]. In fact, the grit-blasting procedure increases the surface area to the interlocking of PDLLA [16]. All blasting parameters were kept constant in order to guarantee similarity of surface roughness between all samples before deposition of the polymer veneer. After grit-blasting, samples were ultrasonically cleaned in isopropyl alcohol during $15 \mathrm{~min}$ and then in distilled water for $15 \mathrm{~min}$. Then, the substrates were modified by etching procedure by using Kroll's reagent (100 ml $\mathrm{H}_{2} \mathrm{O}, 6 \mathrm{ml} \mathrm{HNO}_{3}, 3 \mathrm{ml} \mathrm{HF}$ ) under ultrasonic vibration at $100{ }^{\circ} \mathrm{C}$ for $10 \mathrm{~min}$ in order to remove residual alumina particles from the surfaces [9, 16, 19, 23]. Also, etching was used to promote a nanoroughness leading to a higher interlocking of PDLLA [16]. After etching treatment, the samples were cleaned using the same procedure as previously mentioned.

The modified titanium surfaces were coated with poly (D,L-lactide), $-\left(\mathrm{C}_{6} \mathrm{H}_{8} \mathrm{O}_{4}\right) \mathrm{n}-$, (PDLLA, Resomer R203, Bioenhringer, Ingelheim, Germany) by using spin-coating technique. For spin coating, $2 \mathrm{~g}$ PDLLA powder $(45 \mu \mathrm{m}$ particle size and molecular weight at 29,500 Da) was previously dissolved in $200 \mathrm{ml}$ chloroform under stirring for $12 \mathrm{~h}$ to obtain a homogenous polymeric suspension. The spin coating was performed at $2750 \mathrm{rpm}$ for $20 \mathrm{~s}$. Finally, the specimens were dried at room temperature in a 
laminar flow chamber for $24 \mathrm{~h}$. The roughness of the samples was measured using an optical profilometer (DektakXT, Profilometer, Germany) Ti6Al4V. The veneering PDLLA to Ti6Al4V surfaces showed $R a$ roughness values at $0.5 \mu \mathrm{m} \pm 0.03$, while Ti6Al4V revealed $R a$ roughness values at $1.1 \mu \mathrm{m} \pm 0.2$. Uncoated Ti6Al4V samples were used as control group.

\subsection{Tribocorrosion Tests}

For the tribocorrosion tests, a reciprocating ball-on-plate tribometer (Bruker-UMT-2, USA) was used (Fig. 1). An alumina ball with $10 \mathrm{~mm}$ diameter $\left(\mathrm{Al}_{2} \mathrm{O}_{3}\right.$, Goodfellow, USA) was used as counterbody. The samples were mounted in an acrylic electrochemical cell attached to the tribometer. The tribocorrosion tests were carried out into $30 \mathrm{ml}$ Fusayama's artificial saliva at $37^{\circ} \mathrm{C}$, mimicking the temperature and electrochemical behavior of the oral cavity $[4,5,18,20]$. The composition of the modified Fusayama's artificial saliva used in this study is shown in Table 1 .

Before starting the reciprocating sliding tests, the opencircuit potential (OCP) was recorded on Ti6Al4V for $60 \mathrm{~min}$ using a potentiostat/galvanostat (Gamry 600, USA). A standard two-electrode electrochemical cell was used for the electrochemical measurements, whereas saturated calomel electrode (SCE) was used as the reference electrode and the samples used as the working electrode (exposed area of $0.5 \mathrm{~cm}^{2}$ ) at a normal load of $0.5 \mathrm{~N}$, at a sliding frequency of $1 \mathrm{~Hz}$, and with a linear displacement amplitude of $3 \mathrm{~mm}$ under OCP measurement for $20 \mathrm{~min}$, corresponding to 1200 cycles. One set of each test condition was repeated five times $(n=5)$. After reciprocating sliding testing, the weight loss of the samples was measured by gravimetric analysis.

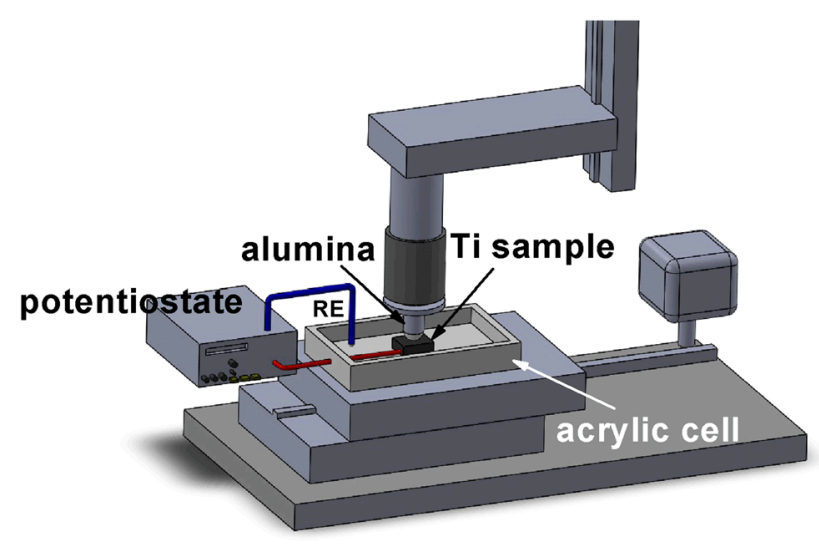

Fig. 1 Schematics of the experimental set up used for tribocorrosion tests
Table 1 Composition of the Fusayama's artificial saliva solution used in this work

\subsection{Microscopic Analysis}

After tribocorrosion tests, samples were ultrasonically cleaned, and the worn surfaces were inspected by Optical Microscopy (Leica DM 2500 M, Leica Microsystems, Germany). Also, Ti6Al4V and PDLLA-to-Ti6Al4V samples were embedded in an acrylic resin and cross-sectioned at angles of $90^{\circ}$ relative to the interface plane. The cross-sectioning was prepared by wet grinding on $\mathrm{SiC}$ paper down to 1200 Mesh followed by polishing with colloidal silica (OPS, diameter of $0.04 \mu \mathrm{m}$ ). The cross-sectioned samples were analyzed by scanning electron microscopy (SEM, JEOL JSM-6390LV, USA) coupled to energy dispersive X-ray spectroscopy (EDX). Polymeric surfaces were sputtercoated with Gold-Palladium before SEM analyses.

\section{Results and Discussion}

\subsection{Tribocorrosion Measurements}

The evolution of OCP before, during, and after sliding for uncoated Ti6Al4V or Ti6Al4V covered with PDLLA are shown in Fig. 2.

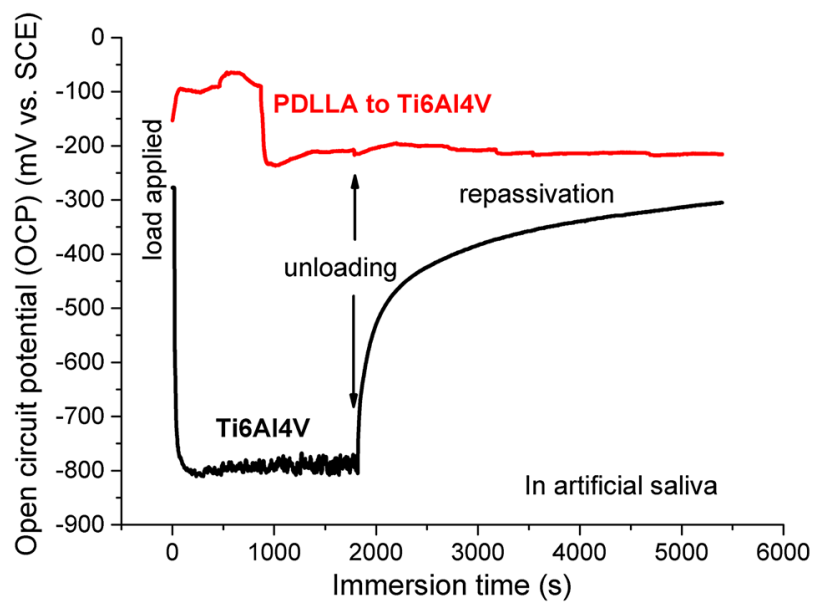

Fig. 2 Evolution of the open-circuit potential (OCP) of PDLLA/ Ti6Al4V or Ti6Al4V immersed in artificial saliva solution at $37{ }^{\circ} \mathrm{C}$ in contact with $\mathrm{Al}_{2} \mathrm{O}_{3}\left(F_{\mathrm{N}}=0.5 \mathrm{~N}, 2 \mathrm{~mm}\right.$ displacement amplitude, $1 \mathrm{~Hz}, 30 \mathrm{~min}$ of sliding) 
Before sliding tests, the OCP of Ti6Al4V immersed in artificial saliva stabilized at quite constant values of about $-270 \mathrm{mV}$ vs. SCE. That indicates the presence of a passive film on the Ti6Al4V surface. Once stabilization was achieved, sliding tests were started (Fig. 2). When the alumina ball was loaded onto that passive film and sliding was started, an abrupt drop in the OCP curve was noticed. That indicated the destruction of the passive titanium film named depassivation exposing the fresh active titanium in the wear track. Thus, a galvanic couple was established between worn and unworn areas in contact with the test solutions as reported by previous studies [4, 5, 18, 21, 22]. At the start of sliding, the OCP measured is a mixed potential value of which depends on the state of undamaged and damaged materials. Then, the OCP decreased to value that was maintained during the entire test indicating that active titanium reacts with the surrounding solution. During the sliding period, the material is not able to recover its protective passive film while the mechanical action of the reciprocating sliding alumina ball was in course. After unloading, the OCP immediately increased to initial values following from re-growth of a passive film on Ti6Al4V in the wear track. That phenomenon is named repassivation (Fig. 2).

The evolution of OCP curve revealed a different behavior on Ti6Al4V coated by PDLLA (Fig. 2). The OCP recorded on PDLLA/Ti6Al4V was not altered during the first 9 min due to the sliding. The PDLLA layer protected the Ti6Al4V against wear and corrosion, as confirmed by the stable OCP values at around $-140 \mathrm{mV}$ vs. SCE. However, an abrupt drop in the OCP curve also occurred after $9 \mathrm{~min}$, corresponding to approximately 540 cycles of sliding. The OCP values decreased down to about $-200 \mathrm{mV}$ vs. SCE and then slightly increased during sliding tests. The decrease of OCP values indicated partial destruction of PDLLA in the wear track and then the destruction of the passive titanium film. However, that exposed a smaller fresh active Ti6Al4V area in the wear track compared to the uncoated Ti6Al4V substrate. In fact, the mixed OCP recorded on PDLLA/Ti6Al4V was associated with a less intense galvanic coupling established between worn and unworn areas in contact with the test solutions. After unloading, the OCP slightly increased following the repassivation (Fig. 2).

The evolution of the coefficient of friction (COF) during sliding for uncoated Ti6Al4V or Ti6Al4V coated by PDLLA against $\mathrm{Al}_{2} \mathrm{O}_{3}$ immersed in artificial saliva at $37{ }^{\circ} \mathrm{C}$ is shown in Fig. 3.

As shown in Fig. 3, the COF achieved a steady state during sliding tests for both uncoated Ti6Al4V and Ti6Al4V coated by PDLLA. Nevertheless, the COF recorded on Ti6Al4V $(0.7 \pm 0.2)$ was significantly higher than that on veneering PDLLA to Ti6Al4V $(0.36 \pm 0.1)$.

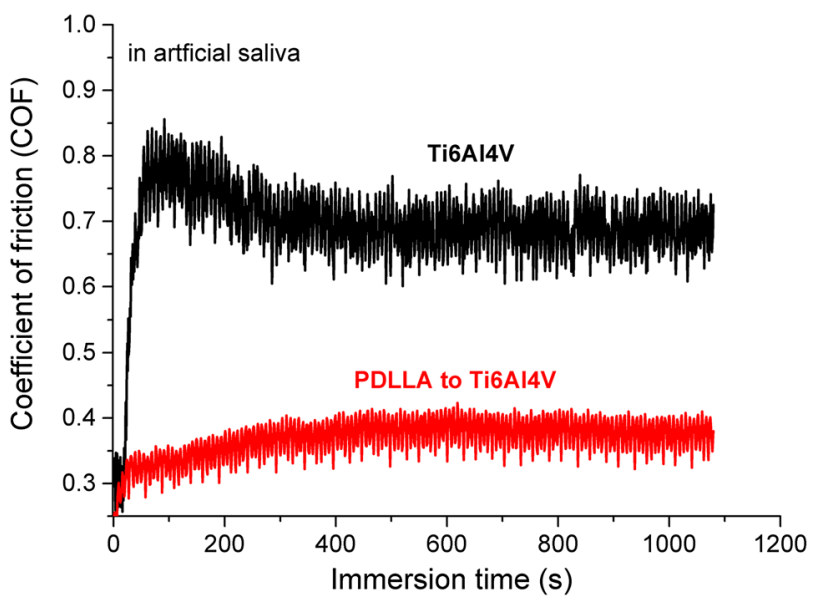

Fig. 3 Evolution of the coefficient of friction with time for Ti6Al4V and PDLLA against $\mathrm{Al}_{2} \mathrm{O}_{3}$ in presence of modified Fusayama's artificial saliva at $37{ }^{\circ} \mathrm{C}\left(F_{\mathrm{N}}=0.5 \mathrm{~N}, 2 \mathrm{~mm}\right.$ displacement amplitude, $1 \mathrm{~Hz}, 30 \mathrm{~min}$ of sliding)

The COF values recorded on Ti6Al4V in this study is similar to those found for titanium sliding in aqueous medium [25]. A slight increase of COF was noticed on the veneering PDLLA to Ti6Al4V, that is associated with the gradual and partial destruction of the PDLLA coating in the wear track during sliding test (Fig. 3). However, the PDLLA can be transferred to the alumina counterface that protected the Ti6Al4V against wear, as noted on the recorded $\mathrm{COF}$ values.

The lower COF noticed for the covered samples can be explained by the self-lubricating capacity of the polymers in general, decreasing the friction and wear [17, 24-27]. Previous studies have reported the tribological behavior of lubricating film of polymers such as UHMWPE; material transfers from UHMWPE to the counter face thus leading to the formation of self-lubricated surfaces. This self-lubricating capacity of the polymers can reduce the $\mathrm{COF}$ and then clinically decrease the wear of contacting surfaces of prostheses and implant joints. All tests demonstrated a much lower friction coefficient and, consequently, a lower wear rate in lubricated sliding than in dry-sliding condition. In our study, the veneering PDLLA supported 9 min of sliding against an alumina ball on $0.5 \mathrm{~N}$ in artificial saliva solution. PDDLA revealed a low friction that can be interesting to support the torquing during the dental implant placement into the bone tissue.

A higher number of oscillations of COF was noticed on uncoated Ti6Al4V than that on PDLLA/Ti6Al4V. The oscillations in the COF during sliding tests can be induced by the abrasive effect of wear debris destroying periodically the titanium surface in the wear track $[4,5,18,21$, 22]. The wear noted on Ti6Al4V in artificial saliva, as tested in our study, is in accordance with the model 
proposed by Landolt et al. [22]. Thus, the detachment of titanium layers and then the ejection of wear debris act like third-body particles in sliding tracks, that may promote oscillations of the $\mathrm{COF}$ as previously reported in literature $[4,5,18,21,22]$. The titanium can be transferred to the alumina counterface; or else, the detached titanium layers and wear debris can be deposited onto the titanium substrate.

\subsection{Morphologic Aspects of Test Sample Surfaces After Sliding}

The micrographs of the wear tracks after the tribocorrosion tests are shown in Fig. 4.

Micrographs of the worn areas after sliding revealed a rougher morphologic aspect of Ti6Al4 $\mathrm{V}$ than on PDLLA surfaces (Fig. 4a, b). A higher level of degradation occurred on uncoated Ti6Al4V surfaces which corroborates with OCP and COF results (Figs. 2 and 3). Regarding wear mechanisms, plastic deformation and groves aligned along the sliding displacement direction were detected on the Ti6Al4V damaged surface as a consequence of adhesive wear (Fig. 4a). Cracks at the Ti6Al4V subsurface were also noticed by SEM analyses of the cross-sectioned samples (Fig. 4c). Those cracks were a consequence of the sliding in the wear track generating wear debris, as reported by previous studies $[4,5,18,21,22]$.

On the cross-sectioned PDLLA/Ti6Al4V assemblies, the PDLLA coating before sliding tests is shown in Fig. 4d.
The thickness of the PDLLA coating was around $50 \mu \mathrm{m}$. After tribocorrosion, PDLLA was detached from the titanium surface, and therefore, the titanium surface was destroyed in the wear track, as seen in Fig. 4e. The tribocorrosion behavior of PDLLA against alumina in presence of artificial saliva was mainly determined by smooth abrasion of the polymeric surface, resulting in low OCP values combined with low friction and wear. In fact, PDLLA acted as a protective barrier decreasing the corrosion and wear of titanium. Nevertheless, the loading and time of sliding determine the removal of PDLLA from titanium surface.

Surface polymeric coatings are commonly used in tribological applications in order to decrease friction and wear of the contacting materials [25]. Considering the possible in vivo conditions of implant placement in bone, the friction and speed of implant torquing should be low to decrease the temperature on bone avoiding tissue necrosis. Also, the time of implant placement is about few minutes that could not affect the detachment of a PDLLA coating, as seen in our study. However, the loading can also determine the detachment of the PDLLA. The PDLLA coatings can become a potential coating on dental implants considering protection against the friction and wear during implant torquing into the bone tissue [4]. In addition, the PDLLA is a bio-absorbable material that can release drugs such as antimicrobials or osteogenic growth factors. Such drugs can accelerate the osseointegration process concerning their influence on inflammation control, migration of osteogenic cells and bone formation around implants [6-10].
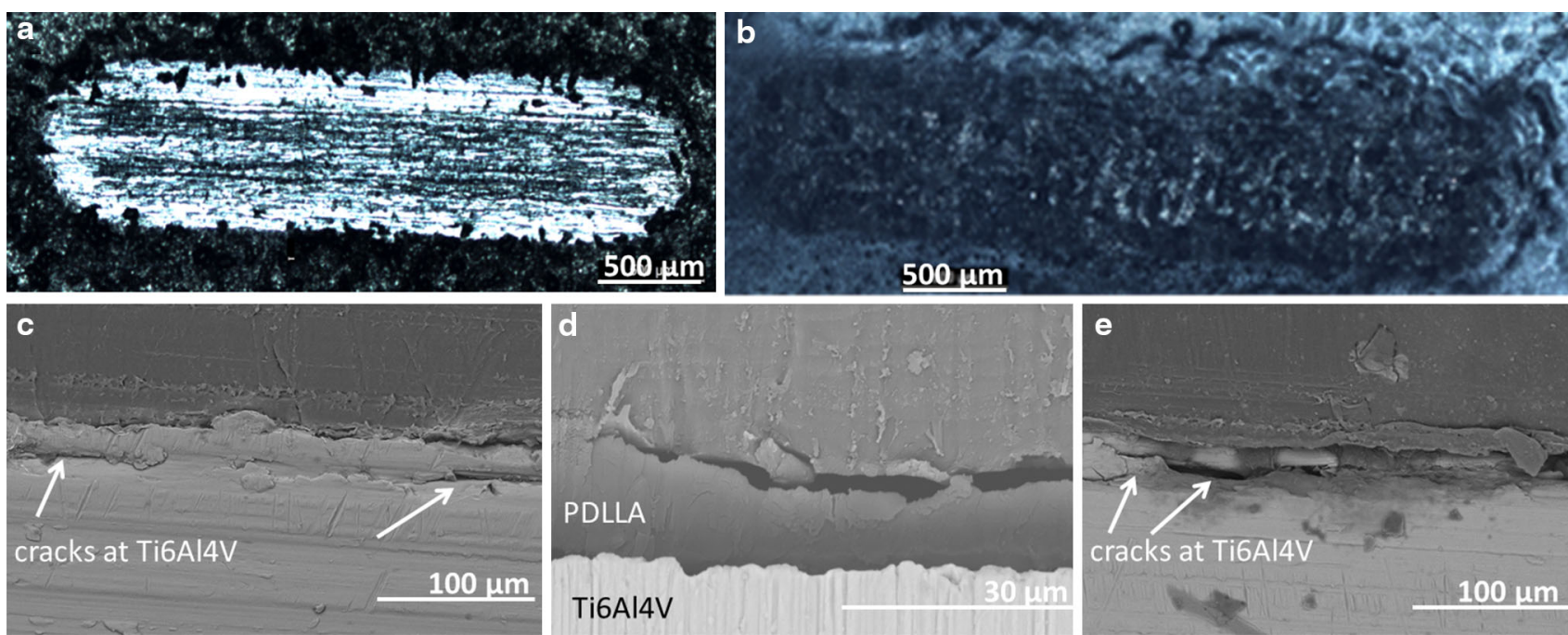

Fig. 4 a, b Optical micrographs of the worn surfaces after reciprocating sliding tests against $\mathrm{Al}_{2} \mathrm{O}_{3}$ immersed in artificial saliva at $37{ }^{\circ} \mathrm{C}$. SEM images of the cross-sectioned $\mathbf{c}$ uncoated Ti6Al4V or e PDLLA/Ti6Al4V interfaces after reciprocating sliding tests against
$\mathrm{Al}_{2} \mathrm{O}_{3}$ immersed in artificial saliva at $37^{\circ} \mathrm{C}$. d SEM images of the cross-sectioned PDLLA/Ti6Al4V interfaces before reciprocating sliding tests 


\section{Conclusions}

The present work evaluated the simultaneous degradation by corrosion and wear of veneering PDLLA to Ti6Al4V in an artificial saliva solution. The results on the COF indicated a lower friction on PDLLA/Ti6Al4V than that on uncoated Ti6Al4V. In fact, PDLLA acted as a protective barrier decreasing the corrosion and wear of titanium. Notwithstanding, the loading and time of sliding determine the removal of PDLLA from titanium surface. Considering the time of protection provided by PDLLA, this bioabsorbable polymer could act as a lubricant layer coating titanium implants during its placement into bone. Then, the PDLLA might remain on implant surface being gradually absorbed during the osseointegration process.

Acknowledgments This work has been supported by FCT (Fundação para a Ciência e Tecnologia-Portugal) in the scope of the project UID/EEA/04436/2013 and EXCL/EMS-TEC/0460/2012.

\section{References}

1. Masmoudi M, Assoul M, Wery M, Abdelhedi R, El Halouani F, Monteil G (2006) Friction and wear behaviour of cp Ti and Ti6Al4V following nitric acid passivation. Appl Surf Sci 253:2237-2243

2. Long M, Rack HJ (1998) Titanium alloys in total joint replacement-a materials science perspective. Biomaterials 19:1621-1639

3. Niinomi M (1998) Mechanical properties of biomedical titanium alloys. Mater Sci Eng A 243:231-236

4. Cruz AH, Souza JC, Henriques M, ROCHA LA (2011) Tribocorrosion and bio-tribocorrosion in the oral environment: The case of dental implants. In: Biomedical tribology. Vol. 2. Nova Science Publishers, Stanford, pp 1-33

5. Souza JCM, Barbosa SL, Ariza E, Celis J-P, Rocha LA (2012) Simultaneous degradation by corrosion and wear of titanium in artificial saliva containing fluorides. Wear 292-293:82-88

6. Gollwitzer H, Ibrahim K, Meyer H et al (2003) Antibacterial poli (D, L-lactic acid) coating of medical implants using a biodegradable drug delivery technology. J Antimicrob Chemother 51:585-591

7. Wildemann B, Lubberstedt M, Haas NP, Raschke M, Schmidmaier G (2004) IGF-I and TGF-beta 1 incorporated in a poly(D, Llactide) implant coating maintain their activity over long-term storage-cell culture studies on primary human osteoblast-like cells. Biomaterials 25:3639-3644

8. Hanawa T (2011) A comprehensive review of techniques for biofunctionalization of titanium. J Periodontal Implant 41:263-272

9. Le Guéhennec L, Soueidan A, Layrolle P, Amouriq Y (2007) Surface treatments of titanium dental implants for rapid osseointegration. Dent Mater 23:844-854

10. Gollwitzer H, Thomas P, Diehl P, Steinhauser E, Summer B, Barnstorf S, Gerdesmeyer L, Mittelmeier W, Stemberger A
(2005) Biomechanical and allergological characteristics of a biodegradable poly(D, L-lactic acid) coating for orthopaedic implants. J Orthop Res 23:802-809

11. Braem A, Mattheys T, Neirinck B, Čeh M, Novak S, Schrooten J, der Biest OV, Vleugels J (2012) Bioactive glass-ceramic coated titanium implants prepared by electrophoretic deposition. Mater Sci Eng C 32:2267-2273

12. Kim HW, Kim HE, Salih V, Knowles JC (2005) Hydroxyapatite and titania sol-gel composite coatings on titanium for hard tissue implants; mechanical and in vitro biological performance. J Biomed Mater Res B Appl Biomater 72:1-8

13. Gollwitzer H, Meyer H, Stemberger A (2003) Implantatinfektionen und Strategien zur antibakteriellen Beschichtung. Trauma Berufskrankh 5:347-352

14. Schmidmaier G, Wildemann B, Stemberger A et al (2001) Biodegradable poly(D, L-lactide) coating of implants for continuous release of growth factors. J Biomed Mater Res 58:49-55

15. Lucke M, Schmidmaier G, Sadoni S et al (2003) Gentamicin coating of metallic implants reduces implant-related osteomyelitis in rats. Bone 32:521-531

16. Patel K, Doyle CS, Yonekure D, James BJ (2010) Effect of surface roughness parameters on thermally strayed PEEK coatings. Surf Coat Technol 204:3567-3572

17. Friedrich K, Alois Schlarb K (2008) Tribology of polymeric nanocomposites. Tribol Interface Eng Ser 55:649-686

18. Souza JCM, Henriques M, Teughels W, Ponthiaux P, Celis J-P, Rocha LA (2015) Wear and corrosion interactions on titanium in oral environment: literature review. J Bio Tribo Corros 1:1-13

19. Ourahmoune R, Salvia M (2011) Effect of sandblasting substrate treatment on single lap shear strength of adhesively bonded PEEK and its composites. In: 18th international conference on composite materials, pp 2-7

20. Souza JC, Ponthiaux P, Henriques M, Oliveira R, Teughels W, Celis JP, Rocha LA (2013) Corrosion behaviour of titanium in the presence of Streptococcus mutans. J Dent 41:528-534

21. Ponthiaux P, Wenger F, Drees D, Celis JP (2004) Electrochemical techniques for studying tribocorrosion processes. Wear 256(5):459-468

22. Landolt D (2006) Electrochemical and materials aspects of tribocorrosion systems. J Phys D Appl Phys 39(15):3121-3127

23. Toptan F, Alves AC, Henriques B, Souza JCM, Coelho R, Silva FS, Rocha LA, Ariza E (2013) Influence of the processing route of porcelain/Ti-6Al-4V interfaces on shear bond stregth. J Mech Behav Biomed Mater 20:327-337

24. Wang Y, Terrell EJ (2013) Influence of coating thickness and substrate elasticity on the tribological performance of PEEK coatings. Wear 303:255-261

25. Neale MJ (2001) The tribology handbook. Butterworth-Heinemann, Oxford

26. Ruggiero A, D’Amato R, Gómez E (2015) Experimental analysis of tribological behavior of UHMWPE against AISI420C and against TiAl6V4 alloy under dry and lubricated conditions. Tribol Int 92:154-161

27. Liu C, Ren L, Arnell RD, Tong J (1999) Abrasive wear behavior of particle reinforced ultrahigh molecular weight polyethylene composites. Wear 225-229:199-204 